\title{
Author Index \\ (Volume 7)
}

Abendroth, M. 1640006

Achiamah-Ampomah, N. 1640003

Andrianov, I. V. 1650006

Awad, I. 1650001

Babu-Nadendla, H. 1640001

Babutskyi, A. 1650004

Bani, M. S. 1650005

Cabedo, L. 1640008

Cheng, K. 1640002, 1640003

Gamez-Perez, J. 1640008

González-Ausejo, J. 1640008

Guan, C. 1640004

Hutař, P. 1640007

Ivanov, A. 1640001

Jacob, A. 1650003

Kalamkarov, A. L. 1650006

Karami, H. 1650005

Karimi, A. 1650005

Khanday, M. A. 1650002

Kuna, M. 1640006

Ladani, L. 1650001

Leese, R. J. 1640001
Lewis, A. 1650004

Mehmanparast, A. 1650003

Mohin, M. A. 1650004

Náhlík, L. 1640007

Navidbakhsh, M. 1650005

Nazir, K. 1650002

Niu, Z. 1640002

Pacheco, P. M. C. L. 1650006

Peng, W. 1640004

Pokorný, P. 1640007

Sánchez-Safont, E. 1640008

Savi, M. A. 1650006

Settgast, C. 1640006

Ševčík, M. 1640007

Shahmohammadi, M. 1650005

Sharif Khodaei, Z. 1640005

Starushenko, G. A. 1650006

Toofanny, H. 1650004

Xu, Y. G. 1650004

Yue, N. 1640005

Zadeh, H. B. 1650005 